\title{
Neonatal Magnesemia in Preterm Neonates Unexposed to Maternal MgSO4 Administration and in Neonates Exposed for Fetal Neuroprotection or Maternal Eclampsia Prevention.
}

\author{
Isabelle Dehaene ( $\nabla$ isabelle.dehaene@ugent.be) \\ Ghent University Hospital https://orcid.org/0000-0002-4826-6946 \\ Tessa Van Steenstraeten \\ Ghent University: Universiteit Gent \\ Kris De Coen \\ University Hospital Ghent: Universitair Ziekenhuis Gent \\ Stefanie De Buyser \\ Ghent University: Universiteit Gent \\ Johan Decruyenaere \\ University Hospital Ghent: Universitair Ziekenhuis Gent \\ Koenraad Smets \\ University Hospital Ghent: Universitair Ziekenhuis Gent \\ Kristien Roelens \\ University Hospital Ghent: Universitair Ziekenhuis Gent
}

\section{Research Article}

Keywords: neonatal magnesemia, neuroprotection, preeclampsia, preterm birth

Posted Date: November 29th, 2021

DOI: https://doi.org/10.21203/rs.3.rs-1108596/v1

License: (c) (i) This work is licensed under a Creative Commons Attribution 4.0 International License. Read Full License 


\section{Abstract}

Objective - To compare neonatal magnesemia in the first fifteen days of neonatal life between three groups: a control group not exposed to $\mathrm{MgSO}_{4}$, a neuroprotection group, and an eclampsia prevention group, and to explore its' associations with child outcomes.

Design -Retrospective single-centre cohort study.

Setting - Tertiary care setting.

Population - Infants admitted at the neonatal intensive care unit born between 24 and 32 weeks' gestation, regardless of etiology of preterm birth.

Methods - Linear mixed regression of neonatal magnesemia on exposure group and day of life. Generalised estimating equations models of child outcomes on neonatal magnesemia according to exposure group and day of life.

Main outcome measures - Neonatal magnesemia $(\mathrm{mmol} / \mathrm{l})$.

Results - Neonatal magnesemia is significantly higher in the preeclampsia group compared to the control and neuroprotection group. On the day of birth, this is irrespective of maternal magnesemia (preeclampsia vs control group), and the maternal total dose or duration of $\mathrm{MgSO}_{4}$ administration (preeclampsia vs neuroprotection group). No differences were found in short-term composite outcome between the three groups.

Conclusions - We found mean differences in neonatal magnesemia between children not exposed to $\mathrm{MgSO}_{4}$ antenatally, children exposed for fetal neuroprotection, and children exposed for maternal eclampsia prevention. A $4 \mathrm{~g}$ loading and $1 \mathrm{~g} / \mathrm{h}$ maintenance dose, for fetal neuroprotection and eclampsia prevention, appears to be safe on the short term for the neonate.

\section{What Is Known}

Magnesium sulfate is a valuable medicine in obstetrics. The main indications are prevention of eclampsia and fetal neuroprotection. The most used dosage is a 4 or 6 grams loading dose and a 1 or 2 grams per hour maintenance dose. It reduces neuromotor disabilities in extreme to moderate preterm born children.

What is new - Maternal concentrations are supraphysiological and the maternal total dose can be high. Concentrations in neonates appear to remain in safe ranges. A dosage of 4 grams loading and $1 \mathrm{gram} /$ hour seems safe for the preterm neonate on the short term.

\section{Introduction}

For several decades now, the administration of magnesium sulphate (MgSO4) is current practice in obstetrics. Historically $\mathrm{MgSO}_{4}$ was used as a tocolytic agent. However, the utility of magnesium sulphate in this context is questionable [1]. Current guidelines recommend the use of MgSO4 for prevention or treatment of seizures in women with (pre)eclampsia or for fetal neuroprotection when extreme or early preterm birth is imminent. $\mathrm{MgSO}_{4}$ administered for fetal neuroprotection reduces the risk of gross motor dysfunction and moderate to severe cerebral palsy [2-8].

While severe adverse effects (such as respiratory depression, cardiac arrest, coma and eventually death) due to an iatrogenic overdose are reported, most maternal adverse effects are minor and well tolerated [9]. Despite widespread use by obstetricians, controversy over unintended adverse neonatal outcomes following maternal magnesium therapy remains. Higher maternal serum magnesium concentrations have been significantly associated with neonatal complications, including low Apgar scores at 1 and 5 minutes, respiratory depression, hypotension, hypotonia, hyporeflexia, neonatal intensive care unit admission, intraventricular hemorrhage, and spontaneous intestinal perforation [10-14]. On the other hand, a recently published systematic review concluded that antenatal $\mathrm{MgSO}_{4}$ administration was not associated with neonatal morbidities or perinatal death [15]. A limitation of most trials examining adverse neonatal effects of maternal MgSO4 administration is grouping all magnesium-exposed neonates together, regardless of its indication. The indication however may have an influence on maternal and neonatal magnesemia.

The primary aim of this study was to compare neonatal magnesemia in the first fifteen days of neonatal life between three groups of infants born before 32 weeks' gestation: a control group that was not exposed to $\mathrm{MgSO}_{4}$ antenatally, a neuroprotection group of neonates whose mothers received $\mathrm{MgSO}_{4}$ for fetal neuroprotection, and a preeclampsia group of neonates whose mothers received $\mathrm{MgSO}_{4}$ to prevent eclampsia. 
Secondary aims were to explore correlations between neonatal magnesemia and maternal serum magnesium concentration, maternal total dose of magnesium, and duration of exposure to magnesium before delivery. We also explored if neonatal magnesemia was associated with adverse short-term outcomes.

\section{Materials And Methods Study design, data source and collection}

We conducted a retrospective single-centre cohort study in Ghent University Hospital, a referral centre for high-risk pregnancies in Belgium. Data on neonates born at a gestational age between $24^{+0}$ and $31^{+6}$ weeks' gestation from January 2012 to December 2015 were extracted from the hospital preterm birth register. The preterm birth register was created in 2016 and provides maternal and neonatal data on demographics, procedures/interventions, diagnoses, short- and long-term morbidities and mortality for preterm births between $24^{+0}$ and $33^{+6}$ weeks' gestation. Obstetrical data were retrospectively entered in the database by senior clinicians. Neonatal data were extracted from an already operational neonatal database and imported into the register. The database was built and managed using the REDCap® electronic data capture tool. The preterm birth register was registered at clinicaltrials.gov (NCT03405116). Patient involvement was limited to consenting in registration and use of the data for scientific purposes. The funding body played no role in the creation of the manuscript.

\section{Population}

Neonates born at a gestational age between $24^{+0}$ and $31^{+6}$ weeks' gestation, regardless of the etiology of preterm birth, admitted at the neonatal intensive care unit were included in this study. Neonates with major congenital malformations are not included in the preterm birth register. A major congenital malformation is defined as a malformation with higher neonatal morbidity or mortality.

\section{Intervention and comparison}

In Ghent University Hospital, the dosage of $\mathrm{MgSO}_{4}$ for fetal neuroprotection is the same as the dosage for eclampsia prevention. A four gram loading dose is given over 15 to 20 minutes and is followed by a maintenance dose of one gram per hour (Zuspan's regimen)[15]. In the setting of fetal neuroprotection, the infusion is stopped when delivery does not occur within 24 hours after start and preterm birth is no longer threatening. If an imminent risk of preterm delivery re-emerges, $\mathrm{MgSO}_{4}$ administration is repeated. In the setting of (pre)eclampsia, $\mathrm{MgSO}_{4}$ infusion is stopped 48 hours after delivery. $\mathrm{MgSO}_{4}$ administration for fetal neuroprotection was introduced in 2014, all neonates not exposed to $\mathrm{MgSO}_{4}$ make up the control group. $\mathrm{MgSO}_{4}$ was not given to the neonates.

\section{Endpoints}

The primary endpoint is neonatal magnesemia, measured repeatedly at unfixed time points in the first fifteen days of neonatal life. If more than one serum magnesium value was available on one day, the first value of that day was taken.

Short-term neonatal core outcome includes neonatal intensive care unit mortality, intraventricular hemorrhage (IVH) and/or periventricular leukomalacia (PVL). IVH and PVL were detected on routine brain ultrasound and respectively scored according to Papille classification criteria and the four-grade classification by de Vries et al [16, 17].

\section{Statistical analysis}

Maternal and neonatal characteristics were compared across the three exposure groups. Continuous variables were compared between groups with one-way ANOVA and pairwise significant differences were identified using the Tukey honest significant differences test. Categorical data on the level of the mother were compared using a Chi-square or Fisher's exact test. Correlations between two continuous variables were assessed using the Pearson correlation coefficient.

To account for clustering due to multiple pregnancies and repeated outcome assessments over days, linear mixed models (LMMs) with two random intercepts were fitted for log-transformed neonatal magnesemia. For the main research question, neonatal day of life (day of birth (= day 0) until day 14), exposure group, and their two-way interaction were included in the fixed effects part of the model. For the other research questions, the models included a three-way interaction between neonatal day of life, exposure group, and maternal magnesemia / total maternal dose of $\mathrm{MgSO}_{4}$ / duration of $\mathrm{MgSO}_{4}$ administration, and all underlying effects. The estimated marginal means with their $95 \%$ confidence interval $(\mathrm{Cl})$ are plotted by neonatal day of life according to exposure group. No indication of multi-collinearity was found based on the variance inflation factor $(<2.5)$.

Generalised estimated equation (GEE) models with an independence correlation structure, Gaussian distribution and identity link function were used to assess the association between neonatal magnesemia and a composite short-term outcome. 
Neonatal and maternal magnesemia, total maternal dose of $\mathrm{MgSO}_{4}$, and duration of $\mathrm{MgSO}_{4}$ administration were log-transformed for all analyses. Regression coefficients from analyses with log-transformed dependent outcome were exponentiated to infer associations regarding the geometric mean. With log-transformed independent variables, the estimated \% change in geometric mean neonatal magnesemia for each $10 \%$ increase in the independent variable was reported.

Subgroup analyses were performed according to exposure group. No analyses regarding maternal magnesemia were performed in the neuroprotection subgroup, due to the limited number of measured maternal magnesemia values $(n=6)$. Evidently, no analyses regarding total maternal dose of $\mathrm{MgSO}_{4}$ and duration of $\mathrm{MgSO}_{4}$ administration were performed in the control subgroup.

All hypothesis testing was performed at the two-sided $5 \%$ significance level. No adjustment for multiple testing was done. All analyses were performed using R version 4.0.5. The package "Ime4" was used to construct the LMMs and the "geepack" package to fit the GEE models.

Ethical considerations

The preterm birth register was approved by the Medical Ethics Committee of Ghent University Hospital on May 5 th 2017 with registration number BE670201732322. This study was approved on February 26th 2018 with registration number BE670201835532. Data were gathered after informed consent was obtained and were handled with professional confidentiality. Withdrawal from the study was possible at any time.

\section{Results}

\section{Demographics and characteristics of the study cohort}

Between 2012 and 2015, 345 neonates were born alive before 32 weeks' gestation and admitted to the neonatal intensive care unit. One hundred and three neonates (29.9\%) were part of a twin and five of a triplet (1.4\%). Two hundred and ninety six mothers were included.

There are 218 neonates in the control group (63.2\%), 68 in the neuroprotection group (19.7\%), and 59 in the preeclampsia group (17.1\%). Demographics and characteristics are summarised in Table 1. In the preeclampsia group, maternal body mass index (BMI) is, on average, higher compared to the other groups $\left(+3.1 \mathrm{~kg} / \mathrm{m}^{2}\right.$ [95\% confidence interval $\left.(\mathrm{Cl}) 1.3,4.9\right]$ versus the control group, and $+2.7 \mathrm{~kg} / \mathrm{m}^{2}[95 \% \mathrm{Cl} 0.5$, $4.8]$ versus the neuroprotection group) and neonatal birth weight is, on average, lower $(-283.0 \mathrm{~g}[95 \% \mathrm{Cl}-390.0,-176.0]$ versus the control group and $-210.7 \mathrm{~g}[95 \% \mathrm{Cl}-348.0,-73.2]$ versus the neuroprotection group). There is a difference in number of multiple pregnancies, with less multiple pregnancies in the preeclampsia group $(-22.7 \%[95 \% \mathrm{Cl}-36.5,-0.9]$ versus the control group, and $-17.3 \%[95 \% \mathrm{Cl}-35.2,0.5]$ versus the neuroprotection group). There are no other significant differences between groups found in our sample. 
Table 1

Demographics and characteristics of the study cohort

\begin{tabular}{|c|c|c|c|c|}
\hline & $\begin{array}{l}\text { No MgSO4 } \\
(\mathrm{N}=218)\end{array}$ & $\begin{array}{l}\text { Neuroprotection } \\
(\mathrm{N}=68)\end{array}$ & $\begin{array}{l}\text { Preeclampsia } \\
(\mathrm{N}=59)\end{array}$ & $\begin{array}{l}\text { Overall } \\
(\mathrm{N}=345)\end{array}$ \\
\hline \multicolumn{5}{|l|}{ Maternal age (years) } \\
\hline Mean (SD) & $30.5(5.1)$ & $30.2(5.8)$ & $30.4(4.8)$ & $30.4(5.2)$ \\
\hline Median [Min, Max] & $30.0[16.0,42.0]$ & $30.0[16.0,43.0]$ & $30.0[17.0,44.0]$ & $30.0[16.0,44.0]$ \\
\hline \multicolumn{5}{|c|}{ Pre-pregnancy BMI (kg/m²) } \\
\hline Mean (SD) & $23.9(4.3)$ & $24.4(5.1)$ & $27.0(7.3)$ & $24.5(5.2)$ \\
\hline Median [Min, Max] & $23.3[15.2,37.2]$ & $23.4[16.5,42.8]$ & $26.0[16.2,64.5]$ & $23.6[15.2,64.5]$ \\
\hline \multicolumn{5}{|l|}{ Parity } \\
\hline Nulliparous & $129(59.2 \%)$ & $46(67.6 \%)$ & $37(62.7 \%)$ & $212(61.4 \%)$ \\
\hline Primiparous & $53(24.3 \%)$ & $11(16.2 \%)$ & $13(22.0 \%)$ & 77 (22.3\%) \\
\hline Multiparous & $36(16.5 \%)$ & $11(16.2 \%)$ & $9(15.3 \%)$ & $56(16.2 \%)$ \\
\hline \multicolumn{5}{|l|}{ Conception } \\
\hline Spontaneous & $156(71.6 \%)$ & $49(72.1 \%)$ & 47 (79.7\%) & $252(73.0 \%)$ \\
\hline Assisted & $62(28.4 \%)$ & $19(27.9 \%)$ & $12(20.3 \%)$ & $93(27.0 \%)$ \\
\hline \multicolumn{5}{|c|}{ Antenatal corticosteroids } \\
\hline No & $17(7.8 \%)$ & $2(2.9 \%)$ & $4(6.8 \%)$ & $23(6.7 \%)$ \\
\hline Yes & $201(92.2 \%)$ & $66(97.1 \%)$ & $55(93.2 \%)$ & $322(93.3 \%)$ \\
\hline \multicolumn{5}{|l|}{ Number of fetuses } \\
\hline Singleton & $139(63.8 \%)$ & $47(69.1 \%)$ & $51(86.4 \%)$ & 237 (68.7\%) \\
\hline Twin & $74(33.9 \%)$ & $21(30.9 \%)$ & $8(13.6 \%)$ & $103(29.9 \%)$ \\
\hline Triplet & $5(2.3 \%)$ & $0(0.0 \%)$ & $0(0.0 \%)$ & $5(1.4 \%)$ \\
\hline \multicolumn{5}{|l|}{ Sex } \\
\hline Male & $120(55.0 \%)$ & $32(47.1 \%)$ & 27 (45.8\%) & 179 (51.9\%) \\
\hline Female & $98(45.0 \%)$ & $36(52.9 \%)$ & 32 (54.2\%) & $166(48.1 \%)$ \\
\hline \multicolumn{5}{|c|}{ Gestational age at birth (weeks) } \\
\hline $24-27+6 w$ & $43(19.7 \%)$ & $21(30.9 \%)$ & $12(20.3 \%)$ & $76(22.0 \%)$ \\
\hline $28-31+6 w$ & $175(80.3 \%)$ & $47(69.1 \%)$ & 47 (79.7\%) & $269(78.0 \%)$ \\
\hline \multicolumn{5}{|l|}{ Birth weight (grams) } \\
\hline Mean (SD) & 1340 (356) & 1260 (396) & 1050 (356) & 1270 (378) \\
\hline Median [Min, Max] & $1360[565,2200]$ & $1280[620,2120]$ & $980[538,2500]$ & $1290[538,2500]$ \\
\hline
\end{tabular}

There is a moderately positive correlation between the total maternal dose of $\mathrm{MgSO}_{4}$ and the maternal magnesemia in the whole population (pearson $=0.64$ ) and in the preeclampsia group (pearson $=0.60$ ). The neonatal magnesemia is, for all days and in all groups, correlated with the neonatal magnesemia of the subsequent day. Table 2 provides a summary of the observed maternal and neonatal magnesium values. 
Table 2

Observed maternal and neonatal (day of birth - neonatal day 7) magnesium values

\begin{tabular}{|c|c|c|c|c|}
\hline & $\begin{array}{l}\text { No MgSO4 } \\
(\mathrm{N}=218)\end{array}$ & $\begin{array}{l}\text { Neuroprotection } \\
(\mathrm{N}=68)\end{array}$ & $\begin{array}{l}\text { Preeclampsia } \\
(\mathrm{N}=59)\end{array}$ & $\begin{array}{l}\text { Overall } \\
(\mathrm{N}=345)\end{array}$ \\
\hline \multicolumn{5}{|c|}{ Maternal magnesemia (mmol/l) } \\
\hline Mean (SD) & $1.00(0.59)$ & $1.23(0.37)$ & $1.91(0.64)$ & $1.49(0.75)$ \\
\hline Median [Min, Max] & $0.75[0.63,2.97]$ & $1.24[0.76,1.64]$ & $1.85[0.74,3.08]$ & $1.52[0.63,3.08]$ \\
\hline Missing & $177(81.2 \%)$ & $62(91.2 \%)$ & $8(13.6 \%)$ & $247(71.6 \%)$ \\
\hline \multicolumn{5}{|c|}{ Maternal total Mg dose (grams) } \\
\hline Mean (SD) & - & $2610(5250)$ & $9190(12200)$ & $5640(9640)$ \\
\hline Median [Min, Max] & - & $838[4,33600]$ & $3570[4,52300]$ & $1480[4,52300]$ \\
\hline Missing & - & $1(1.5 \%)$ & $2(3.4 \%)$ & $221(64.1 \%)$ \\
\hline \multicolumn{5}{|c|}{ Duration MgSO4 infusion (minutes) } \\
\hline Mean (SD) & - & $688(722)$ & $6240(6820)$ & $3240(5400)$ \\
\hline Median [Min, Max] & - & $336[39,3020]$ & $3600[15,31200]$ & $1020[15,31200]$ \\
\hline Missing & - & $1(1.5 \%)$ & $2(3.4 \%)$ & $221(64.1 \%)$ \\
\hline \multicolumn{5}{|c|}{ Neonatal magnesemia, day of birth (mmol/l) } \\
\hline Mean (SD) & $0.82(0.25)$ & $1.12(0.20)$ & $1.65(0.51)$ & $1.02(0.43)$ \\
\hline Median [Min, Max] & $0.77[0.55,2.86]$ & $1.12[0.73,1.81]$ & $1.61[0.79,3.17]$ & $0.84[0.55,3.17]$ \\
\hline Missing & $28(12.8 \%)$ & $10(14.7 \%)$ & $8(13.6 \%)$ & $46(13.3 \%)$ \\
\hline \multicolumn{5}{|c|}{ Neonatal magnesemia, day 1 (mmol/l) } \\
\hline Mean (SD) & $0.92(0.20)$ & $1.13(0.17)$ & $1.51(0.45)$ & $1.06(0.33)$ \\
\hline Median [Min, Max] & $0.89[0.53,2.55]$ & $1.12[0.77,1.63]$ & $1.52[0.76,2.78]$ & $0.95[0.53,2.78]$ \\
\hline Missing & $21(9.6 \%)$ & $6(8.8 \%)$ & $8(13.6 \%)$ & $35(10.1 \%)$ \\
\hline \multicolumn{5}{|c|}{ Neonatal magnesemia, day 2 (mmol/l) } \\
\hline Mean (SD) & $1.04(0.15)$ & $1.17(0.14)$ & $1.39(0.31)$ & $1.13(0.23)$ \\
\hline Median [Min, Max] & $1.02[0.73,2.00]$ & $1.17[0.87,1.58]$ & $1.34[0.89,2.26]$ & $1.07[0.73,2.26]$ \\
\hline Missing & $16(7.3 \%)$ & $4(5.9 \%)$ & $5(8.5 \%)$ & $25(7.2 \%)$ \\
\hline \multicolumn{5}{|c|}{ Neonatal magnesemia, day $3(\mathrm{mmol} / \mathrm{l})$} \\
\hline Mean (SD) & $1.10(0.13)$ & $1.16(0.14)$ & $1.28(0.24)$ & $1.15(0.17)$ \\
\hline Median [Min, Max] & $1.09[0.77,1.88]$ & $1.15[0.88,1.47]$ & $1.23[0.92,1.77]$ & $1.11[0.77,1.88]$ \\
\hline Missing & $24(11.0 \%)$ & $5(7.4 \%)$ & $5(8.5 \%)$ & $34(9.9 \%)$ \\
\hline \multicolumn{5}{|c|}{ Neonatal magnesemia, day 4 (mmol/l) } \\
\hline Mean (SD) & $1.09(0.12)$ & $1.13(0.11)$ & $1.17(0.21)$ & $1.11(0.14)$ \\
\hline Median [Min, Max] & $1.09[0.62,1.59]$ & $1.12[0.92,1.47]$ & $1.15[0.76,1.60]$ & $1.10[0.62,1.60]$ \\
\hline Missing & $34(15.6 \%)$ & $8(11.8 \%)$ & $10(16.9 \%)$ & $52(15.1 \%)$ \\
\hline \multicolumn{5}{|c|}{ Neonatal magnesemia, day 5 (mmol/l) } \\
\hline Mean (SD) & $1.04(0.12)$ & $1.06(0.09)$ & $1.06(0.17)$ & $1.05(0.13)$ \\
\hline Median [Min, Max] & $1.04[0.38,1.46]$ & $1.05[0.91,1.26]$ & $1.04[0.79,1.48]$ & $1.04[0.38,1.48]$ \\
\hline Missing & $47(21.6 \%)$ & $16(23.5 \%)$ & $6(10.2 \%)$ & $69(20.0 \%)$ \\
\hline
\end{tabular}




\begin{tabular}{|lllll|}
\hline & $\begin{array}{l}\text { No MgSO4 } \\
\mathbf{N}=\mathbf{2 1 8})\end{array}$ & $\begin{array}{l}\text { Neuroprotection } \\
\mathbf{( N = 6 8 )}\end{array}$ & $\begin{array}{l}\text { Preeclampsia } \\
\mathbf{( N = 5 9 )}\end{array}$ & $\begin{array}{l}\text { Overall } \\
\mathbf{( N = 3 4 5 )}\end{array}$ \\
\hline Neonatal magnesemia, day 6 (mmol/l) & & & & \\
\hline Mean (SD) & $1.00(0.10)$ & $1.02(0.09)$ & $1.00(0.16)$ & $1.00(0.11)$ \\
\hline Median [Min, Max] & $0.98[0.72,1.39]$ & $1.02[0.81,1.27]$ & $0.98[0.79,1.41]$ & $0.99[0.72,1.41]$ \\
\hline Missing & $68(31.2 \%)$ & $14(20.6 \%)$ & $11(18.6 \%)$ & $93(27.0 \%)$ \\
\hline Neonatal magnesemia, day 7 (mmol/l) & & & & \\
\hline Mean (SD) & $0.96(0.09)$ & $0.96(0.08)$ & $0.93(0.13)$ & $0.95(0.10)$ \\
\hline Median [Min, Max] & $0.95[0.71,1.28]$ & $0.96[0.80,1.10]$ & $0.91[0.72,1.27]$ & $0.95[0.71,1.28]$ \\
\hline Missing & $72(33.0 \%)$ & $30(44.1 \%)$ & $22(37.3 \%)$ & $124(35.9 \%)$ \\
\hline
\end{tabular}

\section{Primary aim (Online Resource S1)}

The distribution of neonatal magnesemia according to neonatal day of life (day 0-14) and indication for $\mathrm{MgSO}_{4}$ administration is visualised in Figure 1.

There is a significant difference in geometric mean neonatal magnesemia between the three groups from the day of birth up to the fourth day of life (day 0-3). No significant differences in neonatal magnesemia between the three exposure groups beyond day four of neonatal life could be found in our sample. The estimated geometric mean neonatal magnesemia (with $95 \% \mathrm{Cl}$ ) per neonatal day of life and group is depicted in Figure 2a and numerically summarised in Online Resource Table S1.

In all three groups, there is no indication of an association of maternal BMI and neonatal birth weight with neonatal magnesemia.

\section{Maternal magnesemia (Online Resource S1)}

In our cohort, there is a significant association between maternal magnesemia and neonatal magnesemia during the first four days of life (day 0-3) in both the control and the preeclampsia group. The association remains significant until the eight day of life (day 0-7) in the preeclampsia group (Online Resource Table S3).

Maternal magnesemia is, on average, higher in the preeclampsia group versus the control group $(+0.70 \mathrm{mmol} / \mathrm{L}[95 \% \mathrm{Cl} 0.50,0.89])(\mathrm{Online}$ Resource Figure S1a).

The estimated geometric mean neonatal magnesemia per neonatal day of life per exposure group for a maternal magnesemia corresponding to the overall geometric mean of $1.30 \mathrm{mmol} / \mathrm{l}$ is depicted in Figure $2 \mathrm{~b}$ and numerically summarised in Online Resource Table S2. Only on the first day of neonatal life (day 0 ), independent of the maternal magnesemia, neonatal magnesemia is significantly higher in the preeclampsia group compared to the control group.

\section{Total maternal dose of $\mathrm{MgSO}_{4}$ (Online Resource S1)}

Most women in the neuroprotection group received $\mathrm{MgSO}_{4}$ for less than 24 hours; only 12 out of 68 women in the neuroprotective group received the maximum dose of 28 grams.

There is a significant association between total maternal dose and neonatal magnesemia during the first four days of life (day 0-3) in both the neuroprotection and the preeclampsia group. The association is significant until the seventh day of life (day 0-6) in the preeclampsia group (Online Resource Table S3).

The geometric mean maternal total dose is, on average, 4.62 times higher in the preeclampsia group versus the neuroprotection group ( $\times 4.62$ $[95 \% \mathrm{Cl} \times 3.13, \times 6.82])$ (Online Resource Figure S1b).

The estimated geometric mean neonatal magnesemia per neonatal day of life per exposure group for a total maternal dose of $\mathrm{MgSO}_{4}$ corresponding the overall geometric mean in these two exposure groups of 23.82 grams, is depicted in Figure $2 \mathrm{c}$ and numerically summarised in Online Resource Table S2. In our cohort, on the two first days of neonatal life (day 0-1) neonatal magnesemia is significantly higher in the preeclampsia group compared to the neuroprotection group, independent of the total maternal $\mathrm{MgSO}_{4}$ dose.

\section{Duration of $\mathrm{MgSO}_{4}$ exposure (Online Resource S1)}


There is a significant association between the duration of $\mathrm{MgSO}_{4}$ administration and the neonatal magnesemia during the first three days of life (day 0-2) in both the neuroprotection and the preeclampsia group. The association remains significant until the seventh day of life (day 0 6) in the preeclampsia group (Online Resource Table S3).

The duration of maternal $\mathrm{MgSO}_{4}$ administration is, on average, 6.96 times higher in the preeclampsia group versus the neuroprotection group (x6.96 [95\% Cl x3.97, x12.18])(Online Resource Figure S1c).

The estimated geometric mean neonatal magnesemia per neonatal day of life per exposure group for a duration of $\mathrm{MgSO}_{4}$ administration corresponding to the overall geometric mean of 850 minutes in these two exposure groups is depicted in Figure $2 \mathrm{~d}$ and numerically summarised in Online Resource Table S2. In our cohort, on the two first days of neonatal life (day 0-1) neonatal magnesemia is significantly higher in the preeclampsia group compared to the neuroprotection group, independent of the duration of $\mathrm{MgSO}_{4}$ administration.

\section{Short-term outcome (Online Resource S1)}

Ninety three neonates (27.0\%) experienced the composite short-term neonatal outcome (mortality, IVH and/or PVL). No significant differences in short-term neonatal outcome between the three exposure groups were identified in our cohort.

\section{Discussion}

\section{Main findings}

We used LMMs to explore the association of neonatal magnesemia with antenatal $\mathrm{MgSO}_{4}$ exposure. In our cohort, neonatal magnesemia is significantly higher in the preeclampsia group compared to the neuroprotection and control group, and in the neuroprotection group compared to the control group, during the first four days of life. There was an association between maternal and neonatal magnesemia during the first four days in the control and preeclampsia group (too few maternal magnesemia values in neuroprotection group). Within the preeclampsia and neuroprotection groups, there was an association between total maternal $\mathrm{MgSO}_{4}$ dose and neonatal magnesemia during the first four days and between duration of administration and neonatal magnesemia during the first three days. Corrected for maternal magnesemia, total dose or duration of administration, the neonatal magnesemia was higher in the preeclampsia group compared to the neuroprotection group on the day of birth. No group differences were found in short-term outcome.

\section{Strengths and limitations}

This is the first study exploring neonatal magnesemia in three distinct groups during the first fifteen days of life. Most studies only take into account the day of birth and/or the day after. Furthermore, few studies compare neonates not exposed to $\mathrm{MgSO}_{4}$ to neonates primarily exposed for neuroprotection or preeclampsia.

We recognise the limitations of a single-centre retrospective study design with a relatively small sample size. Maternal pre-delivery magnesemia levels were missing in the majority of neuroprotection group patients. We could not explore long-term outcomes due to considerable loss to follow-up (Online Resource S2).

Since few women in the neuroprotection group received the maximum dose (28 grams), caution is warranted in making safety statements about 'neuroprotective dosage'. However, results from the preeclampsia group, with higher doses in more pathological circumstances, were reassuring.

A considerable amount of comparisons were made: four research questions, three exposure subgroups, 15 days of life. A risk of false positive significant associations exists. No correction for multiple testing was done, partly because it is not clear at what level the corrections should be done. On the other hand, a lack of power might be present due to small sample sizes, resulting in less associations found than truly present. Our analyses should be considered exploratory.

\section{Interpretation}

Higher levels of neonatal magnesemia in the neuroprotection group compared to unexposed neonates have been reported [11, 18, 19]. The mean neonatal magnesemia in the neuroprotection group of our cohort on day 0 and 1 is comparable to the findings by Garcia et al. (1.10 $\mathrm{mmol} / \mathrm{L})$, but considerably lower than in the study of Basu et al. ( $1.75 \mathrm{mmol} / \mathrm{L})$, which had a different protocol (6g loading dose, $2 \mathrm{~g} / \mathrm{h}$ maintenance) $[11,18]$. Sherwin et al. explored the correlation between maternal and neonatal magnesemia in a group with any indication for $\mathrm{MgSO}_{4}$ [20]. Mean neonatal and maternal magnesemia were significantly associated. It is not clear when neonatal magnesemia was measured. We found an association between neonatal and maternal magnesemia from day 0 to 3 in both control and preeclampsia group. Choi et al. explored the association between maternal BMI and maternal and umbilical cord magnesemia in children born at less than 32 
weeks. Maternal and adjusted umbilical cord magnesemia were not significantly different between BMI categories [21]. In our cohort, there was no association between BMI and neonatal magnesemia.

Two studies found a correlation between the total maternal dose and neonatal magnesemia on day 0 when $\mathrm{MgSO}_{4}$ is given for neuroprotection, as we did [18, 22]. Borja-Del-Rosario et al. excluded patients with preeclampsia [18]. They did not detect a correlation between maternal and neonatal magnesemia, nor between total $\mathrm{MgSO}_{4}$ dose and maternal magnesemia $[18,22]$. We have too few values in the neuroprotection group to confirm or refute these findings.

Nassar et al. reported a higher neonatal magnesemia in a group exposed more than 48 hours to $\mathrm{MgSO}_{4}$ as tocolysis compared to shorter exposure [23].

We cannot explain why neonatal magnesemia was higher in the preeclampsia on the day of birth. It might be due to placental dysfunction, or could be multifactorial.

In general, antenatal $\mathrm{MgSO}_{4}$ is considered to be safe for the neonate [15, 24, 25]. However, there are reports of an association between high neonatal magnesemia and neonatal morbidity and mortality [11, 12, 26, 27]. Basu et al. found that neonatal mortality, in children born between 24 and 32 weeks, increased with increasing neonatal magnesemia. Mortality was highest when neonatal magnesemia exceeded 2.25 mmol/L during the first day of life [11]. In our cohort, none of the neonates in the neuroprotection group had a value exceeding $2.25 \mathrm{mmol} / \mathrm{L}$. In the preeclampsia group, five neonates had a higher magnesemia. There were no cases of neonatal mortality. They found no association with survival without IVH and/or PVL. In the meta-analysis of Shepherd et al., no differences in perinatal death were identified between exposed and unexposed neonates [15]. Only in one (of 11 non-randomised trials) cohort study, with moderate to high bias risk, an increased risk of perinatal death was observed when the dose was more than 48 grams. Possible harms were mostly seen in studies not correcting for confounders, studies with small sample sizes, or in subgroup analyses [15]. Mittendorf et al. concluded that exposure to 50 grams or more of tocolytic $\mathrm{MgSO}_{4}$ is indirectly associated with IVH [28]. We didn't find any between group differences in the proportions of our short-term outcome, which included IVH. In the preeclampsia and neuroprotection group, respectively 36 and two women received a dose of $50 \mathrm{~g}$ or more. Garcia-Alonso et al. studied outcomes in exposed and unexposed children born before 29 weeks. Eighteen per cent of exposed neonates had preeclamptic mothers. They found a significant correlation between $\mathrm{MgSO}_{4}$ dose and neonatal magnesemia on day 0 in the whole group, as we did in the preeclampsia and neuroprotection group. They reported a lower mortality in the exposed group and no differences in neonatal morbidity [29].

\section{Conclusion}

We found mean differences in neonatal magnesemia between children not exposed to $\mathrm{MgSO}_{4}$, children exposed for fetal neuroprotection, and children exposed for maternal eclampsia prevention. After correction for maternal magnesemia, a higher neonatal magnesemia was still present in the preeclampsia group compared to the control group on the day of birth (no comparison with neuroprotection group). After correction for total dose or duration of administration, a higher neonatal magnesemia was still present in the preeclampsia compared to the neuroprotection group till day two of life. When considering neonatal magnesemia per day of neonatal life by exposure group, there was an association with maternal magnesemia, total dose, and duration of administration the first days. A $4 \mathrm{~g}$ loading and $1 \mathrm{~g} / \mathrm{h}$ maintenance dose, for fetal neuroprotection and eclampsia prevention, appears to be safe on the short term for the neonate.

\section{Abbreviations}

$\begin{array}{ll}\text { ACS } & \text { antenatal corticosteroids } \\ \text { BMI } & \text { body mass index } \\ \text { IVH } & \text { intraventricular hemorrhage } \\ \text { MgSO4 } & \text { magnesium sulfate } \\ \text { PVL } & \text { periventricular leukomalacia }\end{array}$

\section{Declarations}

\section{Funding}

Isabelle Dehaene is funded by a scholarship of FWO $(1700520 \mathrm{~N})$. The funding body played no role in the creation of this manuscript. 
The authors have no relevant financial or non-financial interests to disclose.

\section{Author Contribution}

ID: conception, planning, carrying out, analysing, writing. TVS: conception, planning, carrying out, analysing, writing. KDC: conception, planning, writing. SDB: analysing, writing. JDC: writing. KS: writing. KR: conception, planning, writing.

\section{Ethics approval}

The preterm birth register was approved by the Medical Ethics Committee of Ghent University Hospital, Belgium, on May $5^{\text {th }} 2017$ with registration number BE670201732322. This study was approved on February $26^{\text {th }} 2018$ with registration number BE670201835532.

\section{Consents to participate}

Written informed consent was obtained from the parents.

\section{Acknowledgements}

Eline Scheire, Florien Casteels and Celien Van Poeck contributed to data collection.

\section{References}

1. Crowther CA, Brown J, McKinlay CJ, Middleton $P$ (2014) Magnesium sulphate for preventing preterm birth in threatened preterm labour. Cochrane Database Syst Rev (8):CD001060

2. World Health Organization. WHO recommendations for prevention and treatment of pre-eclampsia and eclampsia. Geneva: World Health Organization; 2011. Available from http://apps.who.int/iris/bitstream/handle/10665/44703/9789241548335_eng.pdf;jsessionid=FA6B6DCAFB02BFF9EC95C43C77A72F79? sequence $=1$.

3. World Health Organization. WHO recommendations on interventions to improve preterm birth outcomes. Geneva: World Health Organization; 2011. Available from https://apps.who.int/iris/bitstream/handle/10665/183037/9789241508988_eng.pdf.

4. Marret S, Marpeau L, Zupan-Simunek V, Eurin D, Lévêque C, Hellot M-F, Bénichou J (2007) Magnesium sulphate given before very-preterm birth to protect infant brain: the randomised controlled PREMAG trial*. BJOG 114(3):310-318

5. Shepherd E, Salam RA, Middleton P, Makrides M, Mclntyre S, Badawi N, Crowther C (2017) Antenatal and intrapartum interventions for preventing cerebral palsy: an overview of Cochrane systematic reviews. Cochrane Database Syst Rev 8(8):CD012077

6. Crowther C, Hiller J, Doyle L, Haslam R; Australian Collaborative Trial of Magnesium Sulphate (ACTOMgSO4) Collaborative Group (2003) Effect of magnesium sulfate given for neuroprotection before preterm birth: a randomized controlled trial. JAMA 290(20):2669-2676

7. Altman D, Carroli G, Duley L, Farrell B, Moodley J, Neilson J, Smith D (2002) Do women with pre-eclampsia, and their babies, benefit from magnesium sulphate? The Magpie Trial: a randomised placebo-controlled trial. Lancet 359(9321):1877-1890.

8. Rouse D, Hirtz D, Thom E, Varner M, Spong C, Mercer B, lams J, Wapbner R, Sorokin Y, Alexander J et al (2008) A randomized, controlled trial of magnesium sulfate for the prevention of cerebral palsy. N Engl J Med 359(9):895-905

9. Narasimhulu D, Brown A, Egbert NM, Rojas M, Haberman S, Bhutada A, Minkoff H, Rastogi S (2017) Maternal magnesium therapy, neonatal serum magnesium concentration and immediate neonatal outcomes. J Perinatol 37(12):1297-1303

10. Abbassi-Ghanavati M, Alexander J, Mclntire D, Savani R, Leveno K (2012) Neonatal effects of magnesium sulfate given to the mother. Am J Perinatol 29(10):795-799

11. Basu SK, Chickajajur V, Lopez V, Bhutada A, Pagala M, Rastogi S (2011). Immediate clinical outcomes in preterm neonates receiving antenatal magnesium for neuroprotection. J Perinat Med 40(2):185-189

12. Mittendorf R, Pryde P, Lee K (2003) Association between use of antenatal magnesium sulfate in preterm labor and adverse health outcomes in infants. Am J Obstet Gynecol 189(2):613

13. Riaz M, Porat R, Brodsky N, Hurt H (1998) The effects of maternal magnesium sulfate treatment on newborns: a prospective controlled study. J Perinatol 18(6 Pt 1):449-454

14. Girsen A, Greenberg M, El-Sayed YY, Lee H, Carvalho B, Lyell D (2015) Magnesium sulfate exposure and neonatal intensive care unit admission at term. J Perinatol 35(3):181-185

15. Shepherd E, Salam RA, Manhas D, Synnes A, Middleton P, Makrides M, Crowther C (2019) Antenatal magnesium sulphate and adverse neonatal outcomes: A systematic review and meta-analysis. PLoS Med 16(12):e1002988 
16. Papille LA, Burstein J, Burstein R, Koffler H (1978) Incidence and evolution of subependymal and intraventricular hemorrhage: a study of infants with birth weights less than $1500 \mathrm{gm}$. J Pediatr 92(4): 529-534

17. De Vries L, Eken P, Dubowitz LM (1992) The spectrum of leucomalacia using cranial ultrasound. Behav Brain Res 49 (1): 1-6.

18. Garcia AL, Pumarada PM, Gonzalez CE, Concheiro GA, Suarez AM, Duran Fernandez-Feijoo C, Gonzalez Duran L, Fernandez Lorenzo J (2018) Prenatal Therapy with Magnesium Sulfate and Its Correlation with Neonatal Serum Magnesium Concentration. Am J Perinatol 35(2):170-176

19. Rigo J, Pieltain C, Christmann V, Bonsante F, Moltu SJ, lacobelli S, Marret S (2017) Serum Magnesium Levels in Preterm Infants Are Higher Than Adult Levels: A Systematic Literature Review and Meta-Analysis. Nutrients 9(10)

20. Sherwin C, Balch A, Campbell S, Fredrickson J, Clark E, Varner M, Stockmann C, Kent Korgenski E, Bonkowksy J, Spigarelli M (2014) Maternal magnesium sulfate exposure predicts neonatal magnesium blood concentrations. Basic Clin Pharmacol Toxicol 144(4):318-322

21. Choi Y, Hong J, Hong J, Kom Y, Sung J, Choi S, Oh S, Roh C, Kim H, Sung S, Ahn S, Chang Y (2021) The effects of maternal body mass index and plurality on maternal and umbilical cord serum magnesium levels in preterm birth at less than 32 weeks of gestation. Obstet Gynecol Sci 64(1):62-72

22. Borja-Del-Rosario P, Basu SK, Haberman S, Bhutada A, Rastogi S (2014) Neonatal serum magnesium concentrations are determined by total maternal dose of magnesium sulfate administered for neuroprotection. J Perinat Med 42(2):207-211

23. Nassar A, Sakhel K, Maarouf H, Naasan G, Usta I (2006) Adverse maternal and neonatal outcome of prolonged magnesium sulfate tocolysis. Acta Obstet Gynecol Scand 85:1099-1103

24. Magpie Trial Follow-Up Study Collaborative Group. The Magpie Trial: a randomised trial comparing magnesium sulphate with placebo for pre-eclampsia. Outcome for children at 18 months (2007) BJOG 114(3):289-299

25. Crowther C, Hiller J, Doyle L, Haslam R (2003) Effect of magnesium sulfate given for neuroprotection before preterm birth: a randomized controlled trial. JAMA 290(20):2669-2676

26. Mittendorf R, Covert R, Boman J, Khoshnood B, Lee KS, Siegler M (1997) Is tocolytic magnesium sulphate associated with increased total paediatric mortality? Lancet 350(9090):1517-1518

27. Morag I, Yakubovich D, Stern O, Siman-Tov M, Schushan-Eisen I, Strauss T, Simchen M (2016) Short-term morbidities and neurodevelopmental outcomes in preterm infants exposed to magnesium sulphate treatment. J Paediatr Child Health 52(4):397-401

28. Mittendorf R, Dammann O, Lee K-S (2006) Brain lesions in newborns exposed to high-dose magnesium sulfate during preterm labor. J Perinatol 26:57-63

29. Garcia Alonso L, Pumarada Prieto M, Gonzalez Colmenero E, Concheiro Guisan A, Suarez Albo M, Duran Fernandez-Deijoo C, Gonzal Duran L, Ramon Fernandez Lorenzo J (2017) Prenatal treatment with magnesium sulphate: initial clinical outcomes in pre-term infants less than 29 weeks and correlation with neonatal magnesium levels. An Pediatr (Barc) 86(3):135-141

\section{Tables}

Table 1: Demographics and characteristics of the study cohort 


\begin{tabular}{|c|c|c|c|c|}
\hline & $\begin{array}{l}\text { No MgSO4 } \\
(\mathrm{N}=218)\end{array}$ & $\begin{array}{l}\text { Neuroprotection } \\
(\mathrm{N}=68)\end{array}$ & $\begin{array}{l}\text { Preeclampsia } \\
(\mathrm{N}=59)\end{array}$ & $\begin{array}{l}\text { Overall } \\
(\mathrm{N}=345)\end{array}$ \\
\hline \multicolumn{5}{|l|}{ Maternal age (years) } \\
\hline Mean (SD) & $30.5(5.1)$ & $30.2(5.8)$ & $30.4(4.8)$ & $30.4(5.2)$ \\
\hline Median [Min, Max] & $30.0[16.0,42.0]$ & $30.0[16.0,43.0]$ & $30.0[17.0,44.0]$ & $30.0[16.0,44.0]$ \\
\hline \multicolumn{5}{|c|}{ Pre-pregnancy BMI $\left(\mathrm{kg} / \mathrm{m}^{2}\right)$} \\
\hline Mean (SD) & $23.9(4.3)$ & $24.4(5.1)$ & $27.0(7.3)$ & $24.5(5.2)$ \\
\hline Median [Min, Max] & $23.3[15.2,37.2]$ & $23.4[16.5,42.8]$ & $26.0[16.2,64.5]$ & $23.6[15.2,64.5]$ \\
\hline \multicolumn{5}{|l|}{ Parity } \\
\hline Nulliparous & $129(59.2 \%)$ & $46(67.6 \%)$ & $37(62.7 \%)$ & $212(61.4 \%)$ \\
\hline Primiparous & $53(24.3 \%)$ & $11(16.2 \%)$ & $13(22.0 \%)$ & $77(22.3 \%)$ \\
\hline Multiparous & $36(16.5 \%)$ & $11(16.2 \%)$ & $9(15.3 \%)$ & $56(16.2 \%)$ \\
\hline \multicolumn{5}{|l|}{ Conception } \\
\hline Spontaneous & $156(71.6 \%)$ & $49(72.1 \%)$ & $47(79.7 \%)$ & $252(73.0 \%)$ \\
\hline Assisted & $62(28.4 \%)$ & $19(27.9 \%)$ & $12(20.3 \%)$ & $93(27.0 \%)$ \\
\hline \multicolumn{5}{|c|}{ Antenatal corticosteroids } \\
\hline No & $17(7.8 \%)$ & $2(2.9 \%)$ & $4(6.8 \%)$ & $23(6.7 \%)$ \\
\hline Yes & $201(92.2 \%)$ & $66(97.1 \%)$ & $55(93.2 \%)$ & $322(93.3 \%)$ \\
\hline \multicolumn{5}{|l|}{ Number of fetuses } \\
\hline Singleton & $139(63.8 \%)$ & $47(69.1 \%)$ & $51(86.4 \%)$ & $237(68.7 \%)$ \\
\hline Twin & $74(33.9 \%)$ & $21(30.9 \%)$ & $8(13.6 \%)$ & $103(29.9 \%)$ \\
\hline Triplet & $5(2.3 \%)$ & $0(0.0 \%)$ & $0(0.0 \%)$ & $5(1.4 \%)$ \\
\hline \multicolumn{5}{|l|}{ Sex } \\
\hline Male & $120(55.0 \%)$ & $32(47.1 \%)$ & $27(45.8 \%)$ & $179(51.9 \%)$ \\
\hline Female & $98(45.0 \%)$ & $36(52.9 \%)$ & $32(54.2 \%)$ & $166(48.1 \%)$ \\
\hline \multicolumn{5}{|c|}{ Gestational age at birth (weeks) } \\
\hline $24-27+6 w$ & $43(19.7 \%)$ & $21(30.9 \%)$ & $12(20.3 \%)$ & $76(22.0 \%)$ \\
\hline $28-31+6 w$ & $175(80.3 \%)$ & $47(69.1 \%)$ & $47(79.7 \%)$ & $269(78.0 \%)$ \\
\hline \multicolumn{5}{|l|}{ Birth weight (grams) } \\
\hline Mean (SD) & $1340(356)$ & $1260(396)$ & $1050(356)$ & $1270(378)$ \\
\hline Median [Min, Max] & $1360[565,2200]$ & $1280[620,2120]$ & $980[538,2500]$ & $1290[538,2500]$ \\
\hline
\end{tabular}

Table 2: Observed maternal and neonatal (day of birth - neonatal day 7) magnesium values 


\begin{tabular}{|c|c|c|c|c|}
\hline & $\begin{array}{l}\text { No MgSO4 } \\
(\mathrm{N}=218)\end{array}$ & $\begin{array}{l}\text { Neuroprotection } \\
(\mathrm{N}=68)\end{array}$ & $\begin{array}{l}\text { Preeclampsia } \\
(\mathrm{N}=59)\end{array}$ & $\begin{array}{l}\text { Overall } \\
(\mathrm{N}=345)\end{array}$ \\
\hline \multicolumn{5}{|c|}{ Maternal magnesemia $(\mathrm{mmol} / \mathrm{l})$} \\
\hline Mean (SD) & $1.00(0.59)$ & $1.23(0.37)$ & $1.91(0.64)$ & $1.49(0.75)$ \\
\hline Median [Min, Max] & $0.75[0.63,2.97]$ & $1.24[0.76,1.64]$ & $1.85[0.74,3.08]$ & $1.52[0.63,3.08]$ \\
\hline Missing & $177(81.2 \%)$ & $62(91.2 \%)$ & $8(13.6 \%)$ & $247(71.6 \%)$ \\
\hline \multicolumn{5}{|c|}{ Maternal total Mg dose (grams) } \\
\hline Mean (SD) & - & $2610(5250)$ & $9190(12200)$ & $5640(9640)$ \\
\hline Median [Min, Max] & - & $838[4,33600]$ & $3570[4,52300]$ & $1480[4,52300]$ \\
\hline Missing & - & $1(1.5 \%)$ & $2(3.4 \%)$ & $221(64.1 \%)$ \\
\hline \multicolumn{5}{|c|}{ Duration MgSO4 infusion (minutes) } \\
\hline Mean (SD) & - & $688(722)$ & $6240(6820)$ & $3240(5400)$ \\
\hline Median [Min, Max] & - & $336[39,3020]$ & $3600[15,31200]$ & $1020[15,31200]$ \\
\hline Missing & - & $1(1.5 \%)$ & $2(3.4 \%)$ & $221(64.1 \%)$ \\
\hline \multicolumn{5}{|c|}{ Neonatal magnesemia, day of birth (mmol/l) } \\
\hline Mean (SD) & $0.82(0.25)$ & $1.12(0.20)$ & $1.65(0.51)$ & $1.02(0.43)$ \\
\hline Median [Min, Max] & $0.77[0.55,2.86]$ & $1.12[0.73,1.81]$ & $1.61[0.79,3.17]$ & $0.84[0.55,3.17]$ \\
\hline Missing & $28(12.8 \%)$ & $10(14.7 \%)$ & $8(13.6 \%)$ & $46(13.3 \%)$ \\
\hline \multicolumn{5}{|c|}{ Neonatal magnesemia, day $1(\mathrm{mmol} / \mathrm{l})$} \\
\hline Mean (SD) & $0.92(0.20)$ & $1.13(0.17)$ & $1.51(0.45)$ & $1.06(0.33)$ \\
\hline Median [Min, Max] & $0.89[0.53,2.55]$ & $1.12[0.77,1.63]$ & $1.52[0.76,2.78]$ & $0.95[0.53,2.78]$ \\
\hline Missing & $21(9.6 \%)$ & $6(8.8 \%)$ & $8(13.6 \%)$ & $35(10.1 \%)$ \\
\hline \multicolumn{5}{|c|}{ Neonatal magnesemia, day $2(\mathrm{mmol} / \mathrm{l})$} \\
\hline Mean (SD) & $1.04(0.15)$ & $1.17(0.14)$ & $1.39(0.31)$ & $1.13(0.23)$ \\
\hline Median [Min, Max] & $1.02[0.73,2.00]$ & $1.17[0.87,1.58]$ & $1.34[0.89,2.26]$ & $1.07[0.73,2.26]$ \\
\hline Missing & $16(7.3 \%)$ & $4(5.9 \%)$ & $5(8.5 \%)$ & $25(7.2 \%)$ \\
\hline \multicolumn{5}{|c|}{ Neonatal magnesemia, day $3(\mathrm{mmol} / \mathrm{l})$} \\
\hline Mean (SD) & $1.10(0.13)$ & $1.16(0.14)$ & $1.28(0.24)$ & $1.15(0.17)$ \\
\hline Median [Min, Max] & $1.09[0.77,1.88]$ & $1.15[0.88,1.47]$ & $1.23[0.92,1.77]$ & $1.11[0.77,1.88]$ \\
\hline Missing & $24(11.0 \%)$ & $5(7.4 \%)$ & $5(8.5 \%)$ & $34(9.9 \%)$ \\
\hline \multicolumn{5}{|c|}{ Neonatal magnesemia, day $4(\mathrm{mmol} / \mathrm{l})$} \\
\hline Mean (SD) & $1.09(0.12)$ & $1.13(0.11)$ & $1.17(0.21)$ & $1.11(0.14)$ \\
\hline Median [Min, Max] & $1.09[0.62,1.59]$ & $1.12[0.92,1.47]$ & $1.15[0.76,1.60]$ & $1.10[0.62,1.60]$ \\
\hline Missing & $34(15.6 \%)$ & $8(11.8 \%)$ & $10(16.9 \%)$ & $52(15.1 \%)$ \\
\hline \multicolumn{5}{|c|}{ Neonatal magnesemia, day $5(\mathrm{mmol} / \mathrm{l})$} \\
\hline Mean (SD) & $1.04(0.12)$ & $1.06(0.09)$ & $1.06(0.17)$ & $1.05(0.13)$ \\
\hline Median [Min, Max] & $1.04[0.38,1.46]$ & $1.05[0.91,1.26]$ & $1.04[0.79,1.48]$ & $1.04[0.38,1.48]$ \\
\hline Missing & $47(21.6 \%)$ & $16(23.5 \%)$ & $6(10.2 \%)$ & $69(20.0 \%)$ \\
\hline \multicolumn{5}{|c|}{ Neonatal magnesemia, day $6(\mathrm{mmol} / \mathrm{l})$} \\
\hline Mean (SD) & $1.00(0.10)$ & $1.02(0.09)$ & $1.00(0.16)$ & $1.00(0.11)$ \\
\hline
\end{tabular}




\begin{tabular}{lllll} 
& $\begin{array}{l}\text { No MgSO4 } \\
(\mathbf{N}=\mathbf{2 1 8})\end{array}$ & $\begin{array}{l}\text { Neuroprotection } \\
(\mathbf{N = 6 8 )}\end{array}$ & $\begin{array}{l}\text { Preeclampsia } \\
(\mathbf{N}=59)\end{array}$ & $\begin{array}{l}\text { Overall } \\
(\mathbf{N}=345)\end{array}$ \\
\hline Median [Min, Max] & $0.98[0.72,1.39]$ & $1.02[0.81,1.27]$ & $0.98[0.79,1.41]$ & $0.99[0.72,1.41]$ \\
\hline Missing & $68(31.2 \%)$ & $14(20.6 \%)$ & $11(18.6 \%)$ & $93(27.0 \%)$ \\
\hline Neonatal magnesemia, day 7 (mmol/l) & & & & \\
\hline Mean (SD) & $0.96(0.09)$ & $0.96(0.08)$ & $0.93(0.13)$ & $0.95(0.10)$ \\
\hline Median [Min, Max] & $0.95[0.71,1.28]$ & $0.96[0.80,1.10]$ & $0.91[0.72,1.27]$ & $0.95[0.71,1.28]$ \\
\hline Missing & $72(33.0 \%)$ & $30(44.1 \%)$ & $22(37.3 \%)$ & $124(35.9 \%)$
\end{tabular}

\section{Figures}

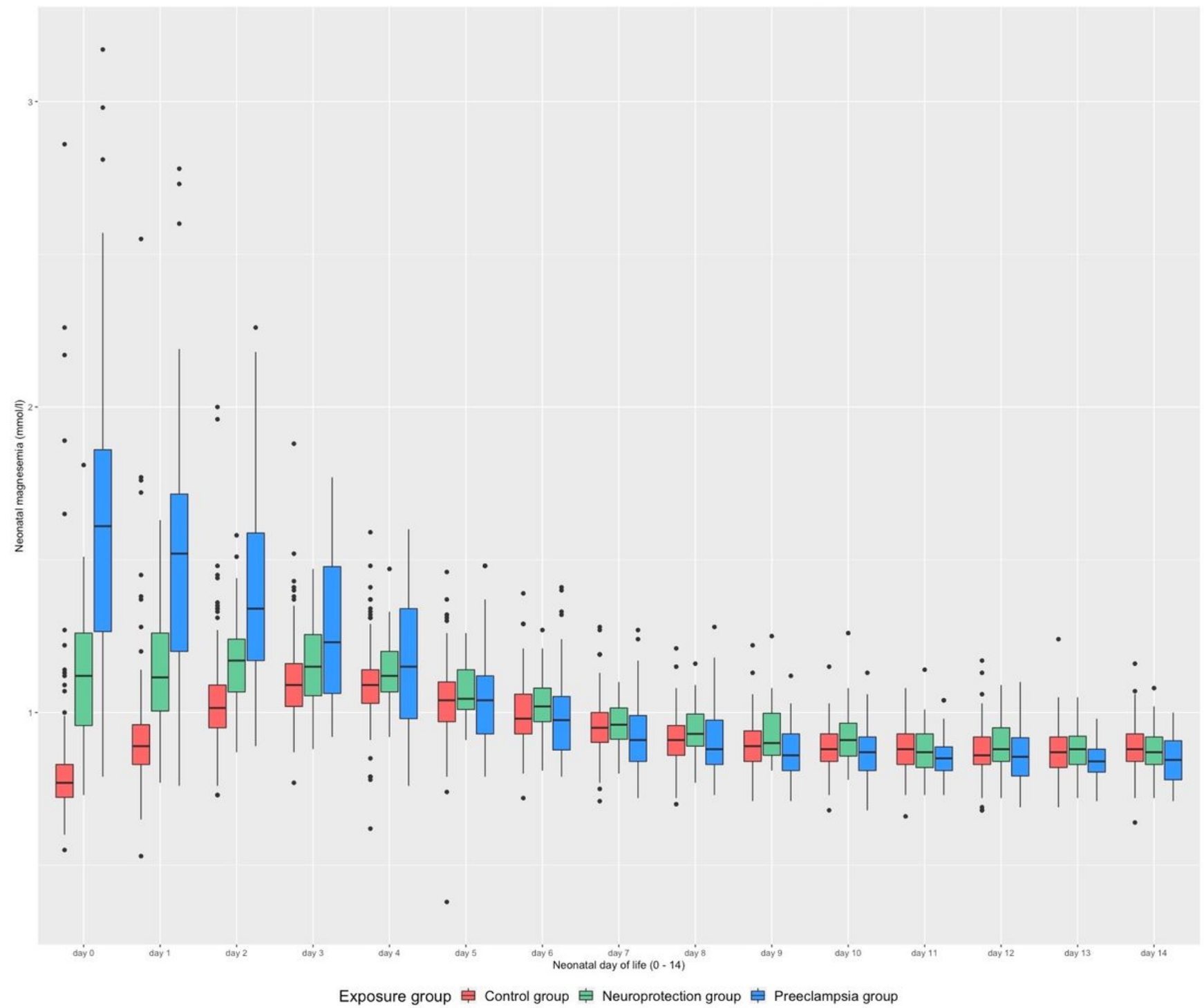

Figure 1

Observed neonatal magnesemia according to indication for MgSO4. 

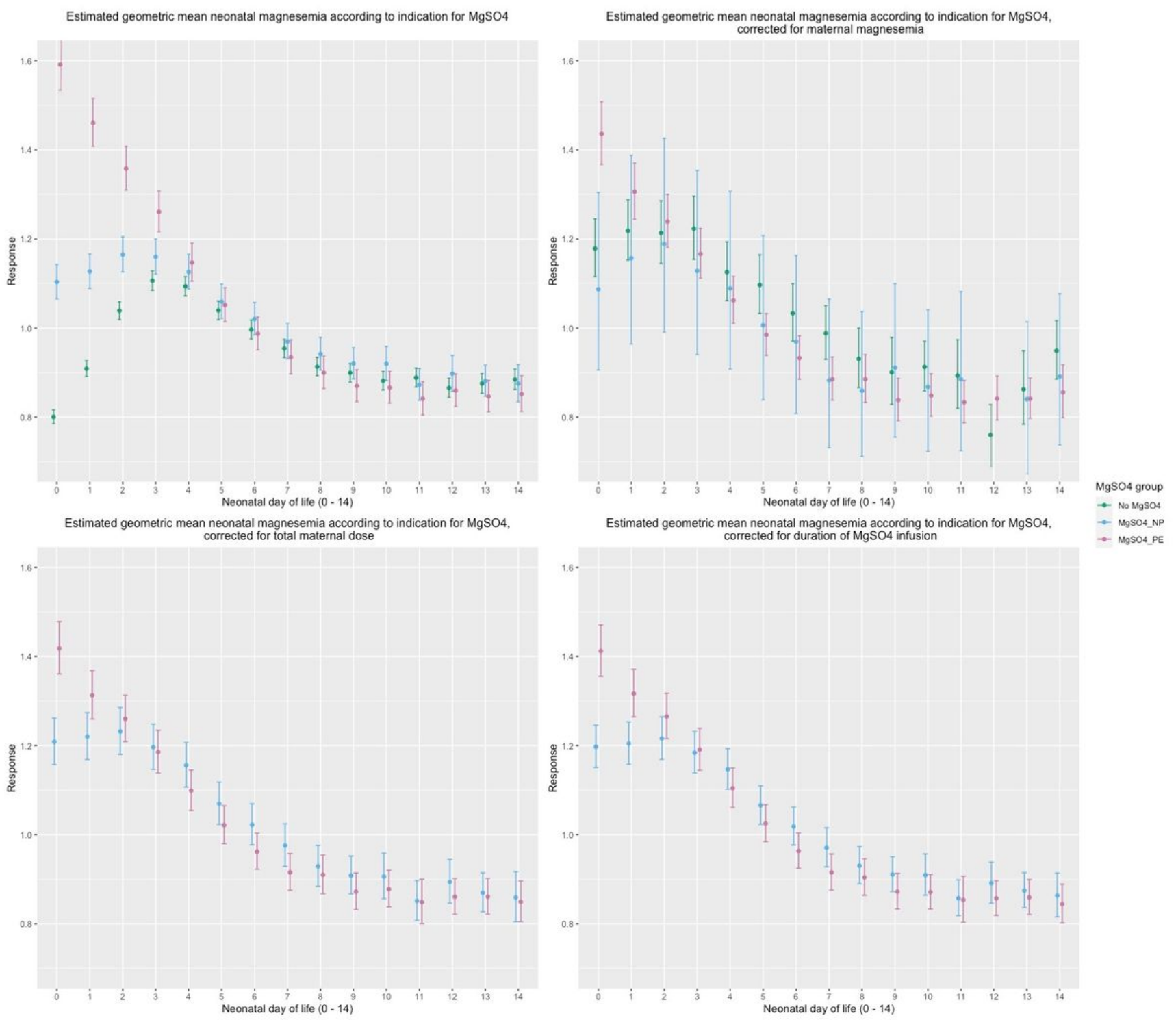

\section{Figure 2}

Estimated geometric mean neonatal magnesemia according to indication for MgSO4.

\section{Supplementary Files}

This is a list of supplementary files associated with this preprint. Click to download.

- FigureS1211123.pdf

- S1211123.docx

- S2211123.docx

- TableS1211123.docx

- Tables2211123.docx

- TableS321123.docx 